\title{
Talking About Food Choices of Former Homeless Young People: Making Sense of Conflicting Discourses of Blame Through Social Worlds Theory
}

\author{
K. Gombert ${ }^{1}$, F. Douglas ${ }^{2}$, K. McArdle ${ }^{3}$, S. Carlisle ${ }^{4}$ \\ ${ }^{1}$ Kingston and St George's University of London, Faculty of Health, Social Care and Education; University of Aberdeen, \\ The Rowett Institute, School of Education (PhD work), UK \\ ${ }^{2}$ Robert Gordon University Aberdeen, School of Nursing and Midwifery, UK \\ ${ }^{3}$ University of Aberdeen, School of Education, UK \\ ${ }^{4}$ University of Aberdeen, The Rowett Institute, UK \\ Correspondence: K. Gombert, Kingston and St George's University of London, Faculty of Health, Social Care and \\ Education; University of Aberdeen, The Rowett Institute, School of Education (PhD work), UK.
}

Received: January 11, 2018

doi:10.11114/ijce.v1i1.3201
Accepted: March 31, $2018 \quad$ Online Published: April 11, 2018

URL: https://doi.org/10.11114/ijce.v1i1.3201

\begin{abstract}
After a pilot study at a charitable youth organisation in the North East of Scotland found no considerable improvements in the food choices of former homeless young people accommodated by the organisation (Perry, 2013), the Foodways and Futures project (2013-2016) set out to explore why. Both members of staff at the same organisation as well as young people were invited to voice their views and opinions on the factors influencing young people's food choices. Whilst everyone's contribution was considered equally informative for our findings, I was attentive to where the information originated from. In this, I found that three conflicting discourses of blame pervade the participants' expressions of the rationales underlying young people's food choices. Trying to make sense of these, I employ Strauss' Social Worlds Theory (1978). I find that the different discourses of blame make sense in the context of the complex organisational structures. In objecting to a tendency in the literature to assign standardised discourse of blame primarily to youth workers' practice, these discourses showcase mutual understanding instead.
\end{abstract}

Keywords: food choices, young people, youth workers, discourse, blame, social worlds theory, youth organisation, food services

\section{Introduction}

Despite the importance of adequate nutrition for growth and development during adolescence, very little is known about food insecurity in homeless young people accessing support from specialist youth homelessness services (Crawford et al., 2014; Thomson, 2014). Instead, young people have been identified as social problems in Western societies since the nineteenth century (Clarke, 2008). When understood as delinquents or youth at risk, young people are often characterised as unhealthy, antisocial, risky, or threatening, within chains of causality linking individuals, poverty, and social problems (Bottrell, 2009). Language of blame and moral judgement are also commonly used in relation to the diet of people who suffer from obesity (De Brun et al., 2012; Shugart, 2014) or serious illnesses such as cancer (Lupton, 2005), and consumer behaviour (Sassatelli, 2004; Shugart, 2014). Also, 'the poor' may often be blamed in public debate as being responsible for unhealthy food intake (Limb, 2014; Lloyd et al., 2011; Purdam, Garratt \& Esmail, 2015; Bottrell, 2009; Thompson et al., 2013; Goode, 2012), although the reasons for their food practices and the underlying socio-economic causes are often underrepresented (Purdam, Garratt \& Esmail, 2015).

The field of youth development has a long and complex past that has often intertwined with other disciplines such as psychology, social work, and education (Cowan, 2012). Over time, many of these disciplines have changed and evolved in an effort to effectively respond to societal demands. Youth programmes of the past were often seen exclusively as a place to play and have fun (Cowan, 2012). Today, however, expectations for youth workers and programmes include the promotion of the overall positive development of the young people within the programme (Cowan, 2012). A common ground of understanding and strong, positive relationships between youth workers and 
youth programme participants have been reported to be the key element to successful programme execution. This is, in terms of meeting programme goals, increasing young people's participation, and ensuring long term commitment to the programmes (Davidson, Evans \& Sicafuse, 2011; Hirsch, 2015; Alcantara, Harper \& Keys, 2015; Nolas, 2014). From this perspective, and as noted above, I elected to consider young people's and staff members' answers as equally informative, whilst remaining attentive to who said what.

I found that discourses of blame are not confined to media and political language, but were used by participants themselves. At the same time, in the relevant literature, I found a tendency to look at either youth workers' or young people's perspectives on the malfunctioning of services instead of combining their perspectives and giving them equal value (Nolas, 2014; Davidson et al., 2011; Kennedy Elder, 2004). In this paper, therefore, I seek to present a counter perspective. Discourses of blame became apparent in particular during interviews and participant observation. I wanted to explore these discourses of blame further, in order to better understand how they relate to the complexities of food choices and how they hence convey such intricacy, and how engagement with discourses of blame can ultimately lead to better provision of the support that is necessary for the young people. Therefore, rather than finding standard oppositional discourses of blame (e.g. by staff members of young people, and vice versa), I found three different blame discourses. Both members of staff and young people engaged in these different discourses, collectively as well as individually. They hence seem conflicting and contradictory, and not easy to reconcile. My research sought to capture the perspectives of both young people and youth workers, "situating culture and meaning making" at the heart of the research and ultimately practice (Nolas, 2014). I therefore saw the utility and relevance for my analysis of Strauss' (1978) Social Worlds Theory (SWT). Although the different discourses appear to be in conflict with each other, I - like Strauss - argue that if understood together, they make sense from each participant's perspective, and in fact make a case for mutual understanding. This again, emphasizes the need for improved awareness about the complexities of young people's lives.

\section{Data Collection}

I employed qualitative research methods: observation took place for ten months at three of the organisation's housing sites; as well as at the Community Centre. These housing sites were selected due to being classified as rural, semi-rural and city, as well as differences in working structures. Observational fieldwork meant an extensive commitment to the participants and intensive full time study of the participants' living environment. During the ten months, 552 hours of observation hours were spent at the housing sites over 69 days, based on an average of eight hours observation each day, plus another 14 days, 112 hours, of observation outwith the official ten months observation period. Interviews to support participant observation took place in an in depth semi-structured manner with young people as well as members of staff. Semi-structured interviews featured different question guides for members of staff as well as young people, but they were both directed towards the same aim of exploring young people's food choices. Also two focus groups with young people contributed to the data. Additional information was gathered through field notes by one young person who took part in the project's peer researcher group. Furthermore, action research methods including photovoice were key to the project, but those are discussed elsewhere (e.g. Gombert et al., 2015; Gombert et al., 2017).

\section{Participants}

Thirty-one members of staff and twelve young people took part in the observation phase across the sites. Five interviews with young people, five interviews with members of staff; and one interview with a board member were conducted. This number was arrived at as together with the data collected from the observation phase, topics started to repeat and the information was considered saturated. Overall, over 40 young people and over 30 members of staff took part in the study.

\section{Discourses of Blame in Foodways and Futures}

In line with Vince and Broussine (2000:26), I define discourses of blame, and the 'blame culture' that maintains and reinforces it, as "a manifestation of the prevalence of defensive postures acted out by one part of the system against another, and which have become entrenched as an integral part of organisational culture" and politics (in Vince \& Saleem, 2004). Shildrick and MacDonald (2013) for example, drawing on life history interviews with sixty men and women in North East England who were caught up in 'the low-pay, no-pay cycle', find that interviewees subscribed to a powerful set of ideas that denied poverty and morally condemned 'the poor'. But I argue for the importance of differentiating between discourses of blame. Depicting participants' discourses as one discourse of blame, in particular in the context of poverty, might be an over-simplification. Whilst the two sets of participants expressed blame, I found that they contextualised the reasons for less healthy food choices instead of viewing them as a consequence of individual ineptitude or moral failure. Such differentiation helps us understand otherwise conflicting ideas about the influences on food choices and the organisation's food services. In particular, three variations in discourses of blame became apparent to me: (1) blaming the organisation, (2) blaming others, (3) self-blame. 


\subsection{Blaming the Organisation}

The structural circumstances at the organisation were being described as reasons behind the unhealthy food choices of young people and the questionable efficacy of food services. In particular members of staff spoke of how the situation used to be better in the past. This was in particular related to the availability of funding for food, e.g.:

I suppose, there [...] seemed to be more money around, and more initiatives, around food, when [...] there was [...] a canteen at that time. (Interview, Member of staff, 26.06.2014)

When I started here 7 or 8 years ago, [...], the kitchen was open every day, [...] for lunches, so that, [...], everybody, all participants would get a lunch. [...]. And unfortunately, due to funding, [...] the [...] lunchtime [...] project finished. We have tried to introduce different things by different groups, [...] but it is all cost, and if it is not cost-effective, cause unfortunately that [...] is what it was down to, means it stops, means that [...] the food stops. (Interview, Member of staff, 12.06.2014)

Members of staff hence seemed to blame a changing economic situation, where money has gradually been restricted: "But I think that the organisation could do masses more. One of the hurdles that we have quite often is that we don't have money for food" (Interview, Member of staff, 15.07.2014).

Whilst there might be truth in 'blaming the situation' now, e.g. funding was more available, such statements also shift responsibility and the realm of influence away from oneself. As another structural factor, the organisation as locality, was named as an unhelpful space for making healthy food choices, e.g.:

There is much food around, this food that is unhealthy all the time. Big boxes of sweets, cakes, biscuits. [...] And there [are] a lot of really unhealthy eaters [...] with chocolate and sweeties, everywhere, all the time. So it's a difficult place to make healthy choices. (Interview, Member of staff, 15.07.2014)

It seemed that in particular members of staff were blaming the organisational setting for how health and food services could be executed. Arguably, this is the case because young people might be rather reluctant in disclosing the context of their food choices as it is a sensitive topic to them. As members of staff are involved in the planning of the services, they may have considered such topics previously and might thus be more critical towards their own services. On top of these challenges, when aiming to improve youth services, it is often the members of staff who are the focus for improvement.

In particular, with regards to such structural blame, we also need to recognise that the organisational setting and the role as a youth worker do indeed create dilemmas for members of staff (Arnold, 2012). Dilemmas occur in situations where competing programme demands make clear-cut responses to the situation difficult (Arnold, 2012), as a member of staff reported:

Because I wouldn't like someone sitting over me when I could eat, what I could eat, [...] that's not right, and what you are doing is wrong and how I would spend my money, [...]. So I can understand from their point of view. And I try really hard when [...] I am shopping with young people [...]. But I do say, have you ever thought about cooking this, or [...] what about fruit and veg. [...]. And [...] we try and introduce them to [...] a wider range of [...] things. (Interview, Member of staff, 26.06.2014)

Discourses of blaming the very organisational structures within which one works and the young people live, is valid in that such structures create challenges and dilemmas. A discourse of organisational blame reveals the participants' shifting responsibility away from the self towards the bigger interrelated picture, over which one individual has seemingly little influence.

\subsection{Blaming Others}

A tendency to blame other people also became apparent. In line with Jones and Perkins (2006), who noted that adults can often perceive young people as in need of assistance rather than being community assets, I found members of staff blaming young people themselves for their food choices and eating behaviours, e.g.:

Everything that 'pings' as I say, because they are all microwave chefs. They can ping bacon, they can ping, they can ping this, they can ping a pie, you know, whatever they can ping, then they will cook, right. (Interview, Member of staff, 12.06.2014)

Young people would blame members of staff in turn:

P5: Well, it's just plain and boring. Every time we go there, it's just pasta. I love pasta but...

P4: Too much pasta.

P5: Yea. The sauce is just horrible. 
P4: That's because it's staff that make it and... (Focus Group, Participant 4, Participant 5, Young Person, 18.07.2014) But they [members of staff] have rubbish advertisements, [...]. They don't prep it properly. [...]. Because then no one knows about it, and no one turns up. (Focus Group, Young Person, 18.07.2014)

However, perhaps surprisingly, I found that members of staff would also blame other members of staff for their lacking efforts in supporting healthy eating at the organisation:

All of the bits that we do, nobody factors in that the young people will have to eat. (Interview, Member of Staff, 15.07.2014)

But some staff are so set in their ways, [...] (Interview, Member of Staff, 12.06.2014)

But I also believe that we don't and never have trained the staff to understand healthy cooking and healthy eating because our staff are nae qualified in it. Our staff are qualified to do a cooking course in order for them to go and do cooking with the young people. There's nae elements of how you do it. (Interview, Member of staff, 02.09.2014)

And similarly, young people would blame other young people, e.g. two young people talking about their peers' cooking behaviour.

P2: They can't be fucked.

P3: There is like, no means really. Because people just buy things that are fast and easy. Instead of [...] standing in a kitchen and making meal.

P2: To be honest, they are fucking, the oven: aye, the microwave: aye, the hob: there is no point.

P3: The hob hardly ever gets used. (Focus Group, Young Person, Participant 2, Participant 3, 22.07.2014)

We see blame not only from one group to the other, i.e. staff to young people and vice versa, but also inter-group blame. Essentially, again, focus is shifted away from oneself onto another person.

\subsection{Blaming the Self}

In addition, crucially, both staff members as well as young people blamed themselves with regards to their food choices and the food services at the organisation. Members of staff primarily referred to how they ("we") are executing food services:

[W] look at just [...], and maybe we need to look into this more, nutritional values. [...], I think, at the moment, [...] we do what we can. What I mean is, [one housing site] does a breakfast club. So for them, for my colleagues up there, at least they know if nothing else, that the ones who come to breakfast club, have eaten that day. If nothing else, they've had breakfast [...] that's good, that's got to be something tangible, they can see that, [...] I think for here, we could do a bit more. (Interview, Member of staff, 12.06.2014)

I think we got into the habit of doing something that is going to fill them up. [...] Whereas it would be better to look at maybe expanding people's [...] tastes, and developing their tastes of different foods. So we should be doing a bit of that. So our main focus at the moment is giving them a [...] robust home cooked meal [...] that is filling, instead of [...] introducing them to new foods and teaching them how to prepare them. So we kind of got caught in feeding them, instead of rather, [...] encouraging them to look at different foods. (Interview, Member of staff, 26.06.2014)

Members of staff were also reflective about the food choices they made themselves:

The member of staff is aware that her own eating habits might be 'convenience' sometimes, [...]. (Fieldnote, 19.03.2014)

Young people also reflected on their own behaviour and noted how they could make better use of the services that are provided:

But at the same time, that is kind of like, me as well, because they do ask you what you want at meetings and sometimes I am just going like, I don't know, and then I am like: actually, go for a shop. (Interview, Young Person, 11.08.2014)

Blaming oneself but blaming others, too, as well as blaming the very structures by which the youth organisation functions, creates conflicts and contradictions in the participants' discourses of blame, which I will explore further.

\section{Making Sense of Conflicting Discourses of Blame Through Social Worlds Theory (SWT)}

Huysman and Elkjaer (2006) remind us that the idea of 'social worlds' has been dealt with in sociology since the 1950s, referring to Park (1952) and Shibutani (1955). A social world is understood as an 'interactive unit', a 'universe of regularized mutual response, communication or discourse' (Shibutani, 1955 in Huysman \& Elkjaer, 2006). Social worlds are not bounded formally but are defined through communication (Shibutani, 1955 in Huysman \& Elkjaer, 2006). What came to be known as Social Worlds Theory (SWT) deals with the articulation of discourses and their 
identities, as well as the social, political, cultural and historical contexts of meaning. Utilising SWT enables me to explore such a multidimensional background to the evolvement of discourses, and do justice to the complexity of factors which influence the variations in discourses of blame the participants engaged in. It also links the discourses to the wider social environments that both members of staff and young people are part of.

More specifically, the concept of 'social worlds' is applied to understand organisational life (Strauss, 1978). Organisations are emotional places, "serving human purposes and dependent on human beings to function. And human beings are emotional animals: subject to anger, fear, surprise, disgust, happiness or joy, ease and unease" (Armstrong, 2000:1 in Vince \& Saleem, 2004). In SWT, work is understood as 'coordinated collective actions', and organisations are understood as 'arenas' of social worlds created and maintained by commitment to organisational activities (Strauss, 1978). These arenas are usually taken as the locus of analysis because, according to Strauss, one cannot understand a single social world in isolation. An important feature of social worlds is their differentiation into subworlds, social worlds' segments (Strauss, 1978). Strauss mentions several steps along which this segmentation process develops and names several sources of segmentation such as space, objects, technology and skills, ideology, intersections with other worlds and recruitment. Considering subworlds as a natural consequence of mutual learning by different groups emerging from social worlds stresses the role of emotion and agency (see e.g. Vince \& Saleem, 2004, Huysman \& Elkjaer, 2006). In this, SWT emphasises the emotional elements of organisational life and work. Considering the organisation's efforts for young people to be committed to the programmes, SWT draws attention to tensions and conflicts reflected in the different commitments to organisational activities.

In light of SWT, we can explain the above conflicting discourses when we view organisational learning as both a social and a political process. It happens with and through other people. It is relational by nature, and therefore there is a likelihood of conflicts, which extends into conflicting and contradictory discourses as such in the study (Gherardi et al., 1998, Vince \& Saleem, 2004). In this sense, emotions are not separable from either learning or politics, and all three are key elements in any attempt at organising. Similar to Strauss, Bakhtin $(1984,1986)$ was an early proponent of the view of language as rooted in social interaction, rather than being an abstract and politically neutral system of signs (in Vasconcelos, 2007). Language is often framed, in his view, within social struggles (Vasconcelos, 2007). In line with Bakhtin, and Strauss, too, the different discourses of blame make clear that the competing priorities of staff members and young people embedded in the learning process generate emotions and political behaviours that often work counter to learning within the organisation (Vince \& Saleem, 2004). That means their statements seem counter-productive to effective support and learning, and yet, the discourses of blame are complexly situated within such subjective interrelations of emotions, interests and behaviours. In this sense, organisational dynamics may be an inhibiting process of reflection and communication within the organisation, undermining the implementation and further development of strategies explicitly designed for organisational learning (Vince \& Saleem, 2004). It is not the discourse as such which could have a negative, or in some instances positive, effect on either members of staff or young people's attitudes, but the discourses work in mutual reinforcement with the organisation structures, somewhat a vicious cycle. According to Vince and Saleem (2007) such complexity further leaves little scope for supporting organisational learning that is transformational which helps to explain the difficulties in transforming the food practices of young people accommodated by the organisation.

What is more, I find that there is a fine line between labelling discourses as blame and naming the problematic issues in order to improve them. Negative statements about sensitive topics of conversation such as food choices might, for example, too easily be labelled as blame. Doing so might leave people aware of likely being labelled as blaming, and ultimately have a rather deconstructive effect on scope for improvement. In fact, whilst I found elements of blame discourses as described above, many members of staff were also cautious and hesitant in how they expressed their observations of the young people's food choices:

I think that they all like the cooking, they all like to take part, they all like to be there and do the cooking. I think, if they, outwith the group setting in their own flats, I don't think that they would cook the same, I don't think that [...], you know, they do that. (Interview, Member of staff, 26.06.2014)

And although they would be cooking it, and they would be choosing the ingredients, [...] it's still a case of making it as cheap as possible, and you know the likes of something with fresh vegetable and good quality food usually is not an option for the young people in the housing project. (Interview, Member of staff, 14.07.2014)

Also, members of staff clearly put the food choices into context and gave reasons for why the young people would make their choices, e.g.

They'll walk into a shop and buy two packets of crisps, and a fizzy juice because they are hungry, rather than thinking of anything else. (Interview, Member of staff, 15.07.2014)

But the dilemma there was, what was in their cupboard, was not healthy. I had yet, for a long period of time, where 
young people are chaotic, I have yet to see somebody to buy fruit and veg. (Interview, Member of staff, 02.09.2014)

I think it depends on the member of staff who is working with the young person. (Interview, Member of staff, 15.07.2014)

What comes up a lot is junk food, well what I call junk food, fast food I should say, not junk food. [...] [M] ost of our, the 16 to 19s are all into their McDonalds, their KFCs, [...]. [...] I'm not slating them, but [...] they tend to eat, a lot of our younger ones, [...] the same things all the time. (Interview, Member of staff, 12.06.2014)

Such discourse of being cautious adds yet another dimension to the above discourses of blame and shows even more nuanced the ways in which participants aimed to express themselves. The dilemmas between naming and blaming were also experienced by myself as researcher in the project (Gombert et al, 2015).

Not recognising the organisation as an arena of social worlds, and the embedded different discourses of blame, but depicting a standardised discourse of blame by staff of young people and vice versa, could suggest poor practice in youth work. But some critiques or suggestions for better practice for youth workers might be inappropriate. In fact, as Jones and Perkins (2006) find, many adults view the lives of young people through their own lenses, thus relating to their younger years. In their study, they examined the "perceptions and experiences of youth and adults engaged in various types of community-based youth-adult relationships". A rating scale on involvement and interaction measured the constructs of "youth involvement", "adult involvement", and "youth-adult interaction" which were completed by 108 participants involved in community groups from 12 communities in 10 US states. Interestingly, relating back to the action research rationale of Foodways and Futures, Jones and Perkins (2006) also find that the study participants who took part in youth-led collaborations were significantly more positive toward youth involvement than participants in adult-led collaborations. Similarly, adults in youth-adult partnerships were significantly more positive toward youth involvement and youth-adult interaction than those adults in adult-led collaborations. Furthermore, in a study by Davidson, Evans and Sicafuse (2011) for example, which analysed the self-reported competency in forming positive relationships with youth of 459 youth workers across 48 US states, nearly all youth workers reported high job satisfaction and an intention to continue working in the field of youth work. They also felt competent in their jobs. The lack of relationship between salary and competency in forming positive relationships with youth may indicate that many youth workers enter and stay in the youth work profession for non-financial reasons (Davidson, Evans \& Sicafuse, 2011). Many youth workers may also enter the field with the desire to pay back what someone else did for them or to make a difference in the community (Davidson, Evans \& Sicafuse, 2011).

After having spent ten months on intensive fieldwork and three years overall with the youth organisation, I found that a lot is asked of youth workers in their position to support the young people as well as of young people in making a transition towards independent living. Youth workers directly or indirectly ask young people to reflect on their experiences, consider others as well as themselves, try new things and explore new ideas (Ingram \& Harris, 2001; Jeffs \& Smith, 2005; Young, 2005). In this, the young person is encouraged to 'disclose' their hopes, their fears, as well as their troubles (Morgan \& Banks, 2010). For youth workers, their role in how to act might not always be easy; and young people may struggle in opening up about their pasts. Depicting the discourses of blame that either staff members or young people would engage in as one dimensional, would therefore mean I blamed the participants myself and ignored the complex social worlds that influenced their discourses.

\section{Conclusions}

The underlying message of this paper is that it is essential for researchers to see programmes from the point of view of the people in them (Larson et al., 2011), which includes both those who 'deliver' and those who 'receive' the programme. Criticism of youth workers' practices, and young people's behaviours, as well as blaming the food practices of 'the poor', may be expressed more easily, than when the complexities of their lives are being observed. Whilst the participants engaged in discourses of blame themselves, differentiating and drawing attention to the conflicts and contradictions between them, makes us realise that there are complex backgrounds to how young people and staff members expressed the factors influencing young people's food choices and the influences on the food environment at the organisation.

As I am only looking at one organisation, my findings might be limited. Nevertheless, I suggest that they make a case for more nuanced and contextualised understandings of discourses of blame. Youth work is a value- and relationship-based practice that relies on young people's voluntary engagement in such relationships (Nolas, 2014). But it also relies on mutual understanding. Differentiating between different discourses of blame by means of SWT reveals more mutual understanding between members of staff and young people than one might at first assume. This implies recognising the impact that emotion and politics have on organisational dynamics (Vince \& Saleem, 2004), and every members', young people's as well as members of staff' emotions as intrinsic to organisational procedures (Vince \& Saleem, 2004). 


\section{Acknowledgements}

This paper has evolved from a 3.5 years PhD studentship in Applied Health Sciences at the University of Aberdeen, entitled Foodways and Futures, under the supervision of Dr Flora Douglas, Dr Sandra Carlisle, Prof Karen McArdle and Prof Geraldine McNeill. This work was supported by the by the Scottish Government's Rural and Environment Science and Analytical Services Division (RESAS). The project has been approved by the Ethics Committee of the Rowett Institute of Nutrition and Health.

\section{References}

Alcantara, L., Harper, G., \& Keys, C. (2015). “There's Gotta Be Some Give and Take": Community Partner Perspectives on Benefits and Contributions Associated With Community Partnerships for Youth'. Youth \& Society, 47(4), 462-485. https://doi.org/10.1177/0044118X12468141

Arnold, M. (2012). 'Dilemmas of Practice: Challenges to Program Quality Encountered by Youth Program Leaders'. In Arnold, M. (Ed.) 'Youth Development Research Briefs'. Accessible at http://oregon.4h.oregonstate.edu/sites/default/files/about/research/2012_complete_briefs.pdf

Bisogni, C., Devine, C., Connors, M., \& Sobal, J. (2002). Who we are and how we eat: A qualitative study of identities in food choice. Journal of Nutrition Education and Behavior, 34, 128-139. https://doi.org/10.1016/S1499-4046(06)60082-1

Black, L. (2012). New Horizons: Understanding the Processes and Practices of Youth Development. In Arnold, M. (Ed.) 'Youth Development Research Briefs'. Accessible at http://oregon.4h.oregonstate.edu/sites/default/files/about/research/2012_complete_briefs.pdf

Bottrell, D. (2009). Dealing With Disadvantage: Resilience and the Social Capital of Young People's Networks. Youth \& Society, 40(4), 476-501. https://doi.org/10.1177/0044118X08327518

Clarke, J. (2008). What's the Problem? Precarious Youth: Marginalisation, Criminalisation and Racialisation. Social Work and Society International Journal Online, 6(2).

Cowan, J. (2012). The Evolving Role of Youth Workers'. In Arnold, M. (Ed.) 'Youth Development Research Briefs. Accessible at http://oregon.4h.oregonstate.edu/sites/default/files/about/research/2012_complete_briefs.pdf

Crawford, B. (2014). Sustaining Dignity? Food insecurity in homeless young people in urban Australia. Health Promotion Journal Of Australia, 25(2), 71-78. https://doi.org/10.1071/HE13090

Davidson, L., Evan, W., \& Sicafuse, L. (2011). Competency in Establishing Positive Relationships With Program Youth: The Impact of Organization and Youth Youth Services, 32(4), 336-354.

Davidson, L., Evan, W., \& Sicafuse, L. (2011). Competency in Establishing Positive Relationships With Program Youth: The Impact of Organisation and Youth Worker Characteristics'. Child \& Youth Services, 32(4), 336-354. https://doi.org/10.1080/0145935X.2011.639242

De Brun, A., McCarthy, M., McKenzie, K., \& McGloin, A. (2012). "Fat is your fault". Gatekeepers to health, attributions of responsibility and the portrayal of gender in the Irish media representation of obesity. Appetite, 62, 17-26. https://doi.org/10.1016/j.appet.2012.11.005

Gombert, K., Douglas, F., McArdle, K., \& Carlisle, S. (2015). Reflections on ethical dilemmas in working with so-called 'vulnerable' and 'hard-to-reach' groups: experiences from the Food ways and Futures project. Educational Action Research Journal.

Gombert, K., Douglas, F., McArdle, K., \& Carlisle, S. (2017). Failure as Learning: Photovoice as Methodology in Research with Marginalised Young People. Excursions Journal, 7(1).

Huysman, M., \& Elkjaer, B. (2006). Organizations as arenas of social worlds; towards an alternative perspective on organizational learning? Available at http://www2.warwick.ac.uk/fac/soc/wbs/conf/olkc/archive/olkc1/papers/163_huysman.pdf

Jones, K., \& Perkins, D. (2006). Youth and Adult Perceptions of Their Relationships Within Community-Based Youth Programs, Youth \& Society, 38(1), 90-109. https://doi.org/10.1177/0044118X06287860

Nolas, S. (2014). Exploring young people's and youthworkersexperiences of spaces for development: creating cultures of participation. Journal of Youth Studies, 17(1), 26-41. https://doi.org/10.1080/13676261.2013.793789

Perry, R. (2013). A study of Diet and Nutrition in Young Homeless People Before and After Supported Accommodation at Aberdeen Foyer.

Purdam, K., Garratt, E., \& Esmail, A. (2015). Hungry? Food Insecurity, Social Stigma and Embarrassment in the UK. 
Sociology, 1-17.

Sassatelli, R. (2004). 'The political morality of food: discourses, contestation, and alternative consumption.' In Harvey, M., McMeekin, A. \& Warde, A. (2004). Qualities of food. Manchester University Press.

Shildrick, T., \& McDonald, R. (2013). Poverty talk: how people experiencing poverty deny their poverty and why they blame 'the poor'. The Sociological Review, 61(2), 285-303. https://doi.org/10.1111/1467-954X.12018

Shugart, H. (2014). Food Fixations. Food, Culture \& Society: An International Journal of Multidisciplinary Research, 17(2). https://doi.org/10.2752/175174414X13871910531665

Strauss, A. (1978). A Social Worlds Perspective. pp. 119-128 in Studies in Symbolic Interaction, Volume 1, Denzin, N (Eds). Greenwich, CT. JAI Press.

Thompson, S., Ryan, T., Montgomery, K., Del Prado Lippman, A., Bender, K., \& Ferguson, K. (2013). Perceptions of Resiliency and Coping: Homeless Young Adults Speak Out. Youth \& Society.

Vasconcelos, A. (2007). The use of Grounded Theory and of Arenas/Social Worlds Theory in Discourse Studies: A Case Study on the Discursive Adaptation of Information Systems.

Vince, R., \& Salem, T. (2004). The Impact of Caution and Blame on Organizational Learning. Management Learning, 35(2), 133-154. https://doi.org/10.1177/1350507604043022

\section{Copyrights}

Copyright for this article is retained by the author(s), with first publication rights granted to the journal.

This is an open-access article distributed under the terms and conditions of the Creative Commons Attribution license which permits unrestricted use, distribution, and reproduction in any medium, provided the original work is properly cited. 